hypothesized that bacteria contain multiple sigma factors, each of which directs the core RNA polymerase to initiate at a different class of promoters but Bacillus subtilis has remained the only organism for which this principle of gene regulation has been demonstrated. Now, however, on page 22 of this issue Westpheling et al. report the identification of multiple holoenzyme forms in the related, but more complex, bacterium Streptomyces coelicolor $^{5}$. One form, containing a sigma factor of relative molecular mass 35,000 $(35 \mathrm{~K})$, has the same promoter specificity as the holoenzymes of vegetatively-growing $E$. coli and $B$. subtilis, an observation that neatly complements the discovery of such a promoter site in S. lividans (M. Buttner and N. Brown, personal communication). The second form of $S$. coelicolor holoenzyme contains polypeptides of $49 \mathrm{~K}$ and $37 \mathrm{~K}$, each of which independently stimulates transcription from a promoter utilized by the $B$. subtilis holoenzyme with a homologous $37 \mathrm{~K}$ factor.

The probable general occurrence of multiple sigma factors in bacteria is apparent from recent elegant studies of the heat-shock response of $E$. coli, in which a sudden increase in temperature stops the production of vegetative gene transcripts ${ }^{6}$ and starts the transcription of 15 heatshock genes which require the product of the $h t p R$ (hin $)^{7,8}$ gene for their expression. Landick et al. ${ }^{9}$ have recently sequenced this gene and shown that it has strong homology in two regions with the sigma factor of vegetative $E$. coli. In agreement with the original sigma hypothesis, one of these domains has the characteristics of a DNAbinding site while - the authors suggest -

\section{0 years ago \\ EARTHQUAKES IN ENGLAND, AND THEIR STUDY}

As no record of the most recent earthquake shock in England has yet found a place in the pages of Nature, perhaps I may be permitted to give the following slight details, collected from the daily papers of Lancashire and London for November 15:-

A shock of earthquake ("severe," yet causing no structural injury) was experienced at Clitheroe, and in the neighbourhood, on the evening of November 14. At about 5.10 p.m. a terrific report, resembling loud thunder, was heard, instantly followed by a strong vibration of the earth, sufficient to induce the inhabitants to run out of their houses into the streets in a terrified state. Much excitement prevailed throughout the borough and neighbourhood of Clitheroe, especially at Low Moor.

The circumstance that this particular part of Lancashire is much subject to earthquake disturbances, makes it specially important that no details of their occurrence be lost to science. Within the last fifty years at least six well-authenticated shocks have been recorded,--in 1835 , $1843,1868,1871,1873$, and 1884 , - and this list might easily be extended. Lancashire, indeed, may be considered as one of the chief areas of disturbance in England, and after Comrie, in Perthshire, perhaps the most important centre of seismic action in Great Britain.

From Nature 31, 172, 25 December 1884. the second is involved in making contacts with the core RNA polymerase. In a complementary study Grossman et al. ${ }^{10}$ have demonstrated that the $h t p R$ gene product functions as a sigma factor in vitro, binding to the core RNA polymerase and directing initiation at a heat-shock promoter not utilized by the vegetative holoenzyme.

The identification of multiple sigma factors in bacteria has proceded by two different routes. In $B$. subtilis and Streptomyces the biochemical characterization of factors of unknown biological function came first and is only now being supplemented by genetic studies such as those of Stragier et al. ${ }^{11}$ who have sequenced the spoIIG gene, a locus required for sporulation, and shown that it has strong homology to the sigma factor of vegetative $E$. coli in regions corresponding to those observed for the $h t p R$ gene. By contrast, the identification of regulatory loci such as $h t p R$ of $E$. coli. and gene 55 of the T4 bacteriophage ${ }^{12}$ preceded their functional assignment as sigma factors.

Are there sigma factors still to find? The answer is probably yes. For example, the nitrogen fixation (nif) genes in Klebsiella and Rhizobium contain a highly conserved promoter sequence which is completely unrelated to those of the other known promoters ${ }^{13,14}$, suggesting that either or both of the products of the regulatory nif $A$ and $g \ln F$ genes function as sigma factors.

How does one sigma factor functionally replace another? Activation of heat-shock genes by the gene product depends critically on the in vivo concentration of the vegetative sigma factor ${ }^{15}$, suggesting that the two factors compete for the core polymerase. In this situation, any mechanism that alters the relative affinity of the factors for the core polymerase might be sufficient to effect the switch. Another trigger for the synthesis of heat-shock proteins in $E$. coli is amino acid starvation ${ }^{10}$, which also results in the inactivation of many promotors transcribed by the vegetative holoenzyme. The molecule that mediates this control is the nucleotide 'alarmone' guanosine 5'diphosphate 3 -diphosphate (ppGpp), which directly affects polymerase function. Heat shock induces the accumulation of another alarmone, AppppA ${ }^{16}$, synthesized in an aberrant reaction by aminoacyl tRNA synthetases ${ }^{17}$. Perhaps such alarmones act by loosening the protein-protein interactions between the vegetative sigma factor and core RNA polymerase, thereby concomitantly switching off a major class of vegetative genes and facilitating the replacement of one sigma factor by another.

The major $70 \mathrm{~K}$ heat-shock protein is one of the few proteins known to be highly conserved between eukaryotes and eubacteria ${ }^{18}$, and the suggested antiquity of the heat-shock response makes it an obvious place to look for clues to the evolution of transcriptional systems. Consequently, it is striking that the ' -35 ' consensus sequence (CNNCTTGAA) of the heat-shock res- ponsive promoters of $E$. coli (but not necessarily all bacterial) genes contains the first half of the inverted repeat consensus sequence (CTNGAANNTTCNAG) of eukaryotic heat-shock responsive genes ${ }^{19}$. Recognition of the latter is by a DNAbinding protein ${ }^{21,22}$ and of the former by a sigma factor. How could such apparently disparate mechanisms have evolved? A simple hypothesis would be that the primeval RNA polymerase, like the present day core of RNA polymerase II, possessed a predilection for melted DNA but lacked sequence-specific recognition, which was conferred by a protein that bound both to the polymerase and to a DNA sequence in the vicinity of easily melted DNA sites. In the evolution of eubacteria, the affinity of this specifying protein for polymerase became greater than that for DNA. By contrast, in the course of eukaryotic evolution, the specifying protein came to have a greater affinity for DNA than polymerase though retaining the ability to interact with it $^{23}$. These considerations imply that the ' -35 ' region recognized by sigma factors must remain assymetric to position the enzyme in the correct orientation to melt the DNA in the ' -10 ' region. In the case of eukaryotic polymerase II promoters, the constraint for directionality would be removed by the one or more specific proteins that identify the corresponding TATA box. This would allow more flexibility in the structure of the specifying region and thus permit multiple binding sites, directing the cooperative binding of more than one molecule of the corresponding regulatory protein (for example, in Drosophila hsp 70 promoters ${ }^{24}$ ) or of distinct regulatory protens with different sequence specificities (for example, in Xenopus hsp 70 promoters ${ }^{25}$ ).

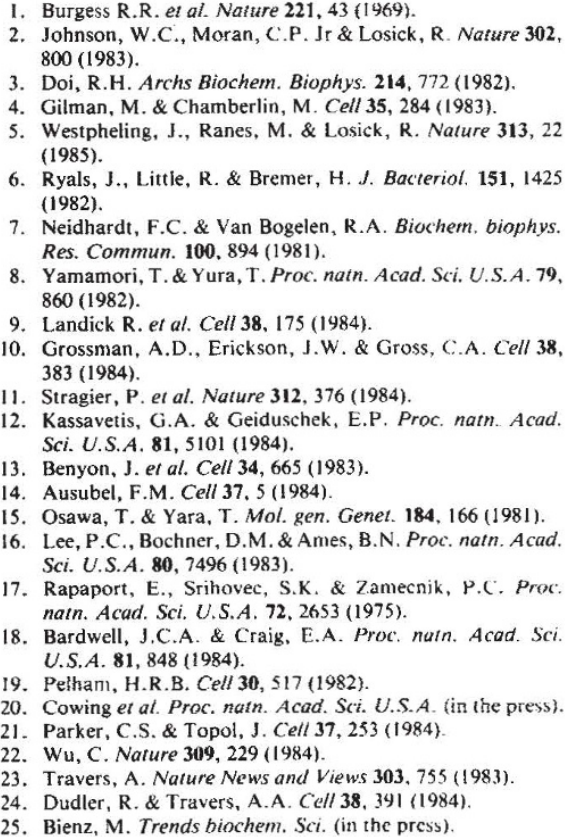

8. Yamamori, T.\& Yura, T. Proc. natn. Acad. Sci. U.S. A. 79, 860 (1982).

9. Landick R. et al. Cell 38, 175 (1984)

10. Grossman, A.D., Erickson, J.W. \& Gross, C.A. Cell 38, 383 (1984)

Stragier, P. et al. Nature 312, 376 (1984).

12. Kassavetis, G.A. \& Geiduschek, E.P. Proc. natn. Acad. Sci. U.S.A. 81, 5101 (1984).

13. Benyon, J. et al. Cell 34, 665 (1983)

14. Ausubel, F.M. Cell 37, 5 (1984)

15. Osawa, T.\& Yara, T. Mol. gen. Genet. 184, 166 (1981).

16. Lee, P.C., Bochner, D.M. \& Ames, B.N. Proc. natn. Acad. Sci. U.S.A. 80, 7496 (1983).

7. Rapaport, E., Srihovec, S.K. \& Zamecnik, P.C. Proc natn. Acad. Sci. U.S.A. 72, $2653(1975)$

18. Bardwell, J.C.A. \& Craig, E.A. Proc. natn. Acad. Sci U.S.A. $81,848(1984)$

Petham, H.R.B. Cell 30, $517(1982)$

20. Cowing et at. Proc, natn. Acad. Sci. U.S.A. (in the press)

21. Parker, C.S. \& Topol, J. Cell 37, 253 (1984).

22. Wu, C. Nature 309, $229(1984)$

23. Travers, A. Nature News and Views 303, 755 (1983).

24. Dudler, R. \& Travers, A.A. Cell 38, 391 (1984).

5. Bienz, M. Trends biochem. Sci. (in the press).

Andrew Travers is at the Medical Research Council Laboratory of Molecular Biology, Hills Road, Cambridge CB2 2QH, UK. 